\title{
Estrogen receptor antagonism uncovers gender-dimorphic suppression of whole body fat oxidation in humans: differential effects of tamoxifen on the GH and gonadal axes
}

\author{
Vita Birzniece ${ }^{1,2,3}$ and Ken K Y Ho ${ }^{1,4}$ \\ ${ }^{1}$ Department of Endocrinology, Garvan Institute of Medical Research, St Vincent's Hospital, Sydney, New South \\ Wales 2010, Australia, ${ }^{2}$ School of Medicine, University of Western Sydney, Sydney, New South Wales 2148, Australia, \\ ${ }^{3}$ The University of NSW, Sydney, New South Wales 2052, Australia and ${ }^{4}$ Centres for Health Research, Princess \\ Alexandra Hospital, The University of Queensland, Brisbane, Queensland 4102, Australia
}

\begin{abstract}
Context: Tamoxifen, a selective estrogen receptor modulator, suppresses GH secretion in women but not in men. It increases testosterone levels in men. As GH and testosterone stimulate fat metabolism, the metabolic consequences of tamoxifen may be greater in women than in men.

Objective: To determine whether tamoxifen suppresses fat oxidation (Fox) to a greater degree in women than in men.

Design: An open-label study of ten healthy postmenopausal women and ten healthy men receiving 2-week treatment with tamoxifen (20 mg/day).

Endpoint measures: GH response to arginine stimulation, serum levels of IGF1, testosterone and LH (men only), sex hormone binding globulin (SHBG) and whole body basal and postprandial Fox.

Results: In women, tamoxifen significantly reduced the mean GH response to arginine stimulation $(\Delta-87 \%, P<0.05)$ and circulating IGF1 levels $(\Delta-23.5 \pm 5.4 \%, P<0.01)$. Tamoxifen reduced postprandial Fox in women $(\Delta-34.6 \pm 10.3 \% ; P<0.05)$. In men, tamoxifen did not affect the GH response to arginine stimulation but significantly reduced mean IGF1 levels $(\Delta-24.8 \pm 6.1 \%, P<0.01)$. Tamoxifen increased mean testosterone levels $(\Delta 52 \pm 14.2 \% ; P<0.01)$. Fox was not significantly affected by tamoxifen in men.

Conclusion: Tamoxifen attenuated the GH response to stimulation and reduced postprandial Fox in women but not in men. We conclude that at a therapeutic dose, the suppressive effect of tamoxifen on fat metabolism is gender-dependent. Higher testosterone levels may mitigate the suppression of $\mathrm{GH}$ secretion and Fox during tamoxifen treatment in men.
\end{abstract}

\section{Introduction}

Estrogen plays a major role in the regulation of growth hormone $(\mathrm{GH})$ secretion which is stimulated centrally by estradiol $\left(\mathrm{E}_{2}\right)$ derived locally from aromatisation of testosterone in both men and women $(1,2)$. In men, estrogen not only regulates the $\mathrm{GH}$-insulin-like growth factor (IGF) axis, but also the pituitary-gonadal axis, as the inhibition of luteinizing hormone (LH) secretion by testosterone requires prior aromatization to $\mathrm{E}_{2}$ (3). Thus, locally produced estrogen in the brain regulates the $\mathrm{GH}$ and gonadal system.

We recently reported that tamoxifen, a selective estrogen receptor modulator (SERM) that blocks central estrogen action, reduces GH secretion in women but not in men (4). Tamoxifen also enhanced LH secretion and increased testosterone levels in men (5). As testosterone stimulates GH secretion (1), it is conceivable that the (c) 2015 European Society of Endocrinology Printed in Great Britain
Published by Bioscientifica Ltd. 
higher testosterone levels induced by tamoxifen in men mitigated the suppression of GH release. Thus, central estrogen blockade is expected to result in a lesser effect on the GH-IGF1 axis in men than women.

$\mathrm{GH}$ and testosterone both regulate fat mass. Fat mass is increased in GH-deficient and hypogonadal men and reversed by $\mathrm{GH}$ and testosterone replacements $(6,7,8,9$, $10,11)$. GH regulates fat mass via stimulation of lipolysis and fat oxidation (Fox) (12). Testosterone also stimulates Fox $(13,14,15)$. Our group recently reported that the stimulatory effects of testosterone on whole body Fox occurs primarily acting in extra-hepatic tissues (16). Moreover, testosterone and GH stimulate whole body Fox when used alone and more so in combination $(13,17)$. Thus, GH and testosterone interact in the regulation of Fox and fat mass.

As both GH and testosterone regulate fat metabolism and central estrogen blockade are expected to result in gender-specific effects on the GH-IGF1 and gonadal axes, we postulated that the effect of tamoxifen on fatty acid oxidation is different between women and men. The present investigation tests the hypothesis that tamoxifen exerts a greater suppressive effect on Fox in women than in men.

\section{Methods}

\section{Subjects}

Ten healthy postmenopausal women (mean age $64 \pm 2$ years; mean BMI $25 \pm 1 \mathrm{~kg} / \mathrm{m}^{2}$ ) and ten healthy men (mean age $65 \pm 3$ years; mean BMI $26 \pm 1 \mathrm{~kg} / \mathrm{m}^{2}$ ) were recruited from the community through advertisements. Study participants were in good general health and had normal haematological tests, renal and hepatic function. Exclusion criteria included $\mathrm{BMI} \geq 30 \mathrm{~kg} / \mathrm{m}^{2}$, hypothalamic or pituitary disorders, diabetes mellitus and chronic renal or hepatic illnesses. Subjects were not taking hormone replacement therapy or any medications known to interfere with endocrine systems. Throughout the study, subjects were instructed to follow their usual diet and physical activity. St Vincent's Hospital Human Research Ethics Committee approved the study, which was conducted in accordance with the principles of the Declaration of Helsinki. The study was registered with the Australian New Zealand Clinical Trials Registry (ACTRN12607000586415).

\section{Study design}

This was an open labelled study of tamoxifen (Genox) administration. The dose of tamoxifen was $20 \mathrm{mg} /$ day. Subjects were studied in the Clinical Research Facility, Garvan Institute of Medical Research at baseline and after
2 weeks of tamoxifen treatment. All participants were asked to fast the night before each visit. On each visit assessment of GH status using the arginine stimulation test was performed, whole body basal and postprandial Fox was measured, as well as serum IGF1, LH, testosterone, and sex hormone binding globulin (SHBG) levels. Circulating LH levels were measured in five samples taken every 30 min over a 2 -h period during the arginine stimulation test. Study bloods were collected and serum samples were obtained by centrifugation, and stored at $-80^{\circ} \mathrm{C}$ until analysis. Data on neuroendocrine effects of tamoxifen in women and in men have been previously published $(2,5)$.

\section{Arginine stimulation test}

Subjects rested on a bed for at least $30 \mathrm{~min}$ before the baseline blood samples were taken. Thirty grams of L-arginine hydrochloride (Phebra Pty Ltd, Lane Cove West, NSW, Australia) was infused over a $30 \mathrm{~min}$ period. Blood samples for $\mathrm{GH}$ level measurements were taken at baseline and 30, 60, 90 and 120 min after commencement of arginine infusion. In healthy subjects, the arginine stimulation test has been shown to have good intraindividual reproducibility (18).

\section{Substrate oxidation and resting energy expenditure assessment}

Resting energy expenditure (REE) and substrate metabolism (Fox and carbohydrate oxidation (Cox)) were quantified after an overnight fast by indirect calorimetry using a metabolic monitor (ParvoMedics, Sandy, UT, USA), which was calibrated against standard gases before each study. Subjects were placed on a bed and allowed to rest for at least $30 \mathrm{~min}$. A clear plastic hood was placed loosely over the subject's head and shoulders for a 20 min period. $\mathrm{O}_{2}$ consumption and $\mathrm{CO}_{2}$ production were measured and $\mathrm{REE}$, Fox and Cox were estimated using weight-based equations adjusted from Ferrannini (19). The measurement was repeated at 30 and $90 \mathrm{~min}$ after liquid standardized mixed meal containing $13 \mathrm{~g}$ protein, $11.4 \mathrm{~g}$ fat and $50.1 \mathrm{~g}$ carbohydrates (Ensure Plus, Abbott Laboratories). REE is expressed as kcal/day, Fox and Cox are expressed as $\mathrm{mg} / \mathrm{min}$. The mean intra-subject coefficients of variation (CV) for REE and Fox at our institution are 4.2 and $4 \%$ respectively (20).

\section{Analytical methods}

All samples for any individual were measured in the same assay run for each analyte. Serum GH was measured by 
ELISA calibrated against the WHO IS 80/505 (Bioclone Australia Pty Ltd, Marrickville, NSW, Australia) with sensitivity of $<0.1 \mathrm{mIU} / \mathrm{l}$. The $\mathrm{CV}$ for $\mathrm{GH}$ were $4.4 \%$ at $6.5 \mathrm{mIU} / \mathrm{l}$ and $3.5 \%$ at $17.6 \mathrm{mIU} / \mathrm{l}$. Serum IGF1 was measured by RIA after acid ethanol extraction as previously described (2). The CV for IGF1 were $8.3 \%$ at $14.7 \mathrm{nmol} / 1$ and $7.4 \%$ at $28.6 \mathrm{nmol} / \mathrm{l}$. Serum SHBG was measured using a commercial immunoassay (Immulite 2000, Siemens Medical Solution Diagnostics, Los Angeles, CA, USA). The CV for SHBG at 5.3 and $86.2 \mathrm{nmol} / \mathrm{l}$ were 5.0 and $7.5 \%$ respectively. Normal range for SHBG: females $20-110 \mathrm{nmol} / \mathrm{l}$, males $>50$ years 20-90 nmol/l. Serum testosterone was measured using a commercial immunoassay (Immulite 2000, Siemens Medical Solution Diagnostics). The inter-assay CV for testosterone at 3.6 and $23 \mathrm{nmol} / \mathrm{l}$ were 9.3 and $9.0 \%$ respectively. Normal range for testosterone in males $>50$ years $8-32 \mathrm{nmol} / \mathrm{l}$. Serum LH was measured by ELISA calibrated against the WHO 2nd IS 80/552 (Diagnostics Biochem Canada, Inc., Dorchester, ON, Canada). The CV for $\mathrm{LH}$ were $5.1 \%$ at $5.15 \mathrm{IU} / \mathrm{l}$ and $8.1 \%$ at $17.4 \mathrm{mIU} / \mathrm{l}$. Normal range for testosterone in males 1.7-8.6 IU/l. Triglyceride (TG), HDL and total cholesterol were measured using Enzyme Colorimetric method by Cobas 701 auto-analyser (Roche Diagnostics). The inter-assay $\mathrm{CV}$ for TG was $2.6 \%$ at $2.9 \mathrm{mmol} / \mathrm{l}$, for total cholesterol
$2.7 \%$ at $7.1 \mathrm{mmol} / \mathrm{l}$, and for HDL-cholesterol was 3.6\% at $1.4 \mathrm{mmol} / \mathrm{l}$. Normal ranges for TG $0-2.0 \mathrm{mM} / \mathrm{l}$, HDL cholesterol $>1.0 \mathrm{mM} / \mathrm{l}$, and for total cholesterol $0-6.0 \mathrm{mM} / 1$.

The study was registered with the Australian New Zealand Clinical Trials Registry (ACTRN12607000586415).

\section{Statistical analysis}

As the GH response to arginine displays large inter-subject variation and is not normally distributed, data were logarithmically transformed for parametric analysis. The $\mathrm{GH}$ response to arginine and changes in circulating $\mathrm{LH}$ levels were analysed by repeated measures ANOVA. Peak GH levels were calculated as maximum increment over pre-stimulated GH concentration. Calculated free testosterone (CFT) levels were derived from total testosterone and SHBG levels using the Ly and Handelsman method (21). Treatment effects were assessed using paired t-tests with Bonferroni's correction and comparison between treatments analysed by factorial ANOVA where appropriate. Results were expressed as mean with s.E.M. and a $P$ value of $<0.05$ was considered to be significant. Statistical analysis was undertaken using the Statistical Software Package SPSS (IBM SPSS Statistics 21) and GraphPad Software Prism 6 (GraphPad Software, Inc., La Jolla, CA, USA).

Table 1 Endpoint measures at baseline (nil) and during the treatment with tamoxifen (20 mg/day). Data are expressed as means \pm S.E.M. Conversion factor for $\mathrm{GH}: 1 \mathrm{mlU} / \mathrm{l}=0.33 \mu \mathrm{g} / \mathrm{l}$.

\begin{tabular}{|c|c|c|c|c|}
\hline \multirow[b]{2}{*}{ Outcome measures } & \multicolumn{2}{|c|}{ Women } & \multicolumn{2}{|c|}{ Men } \\
\hline & Nil & Tamoxifen & Nil & Tamoxifen \\
\hline Weight (kg) & $66.9 \pm 3.3$ & $68.2 \pm 3.3^{\dagger}$ & $80.6 \pm 4.0^{\ddagger}$ & $80.7 \pm 4.1$ \\
\hline Peak GH (mIU/l) & $13.6 \pm 4.4$ & $4.2 \pm 1.4^{*}$ & $13.8 \pm 5.2$ & $9.1 \pm 2.9$ \\
\hline GH AUC (mIU/l per 120 min) & $745.8 \pm 290$ & $51.3 \pm 161 *$ & $731.2 \pm 348$ & $526.1 \pm 197$ \\
\hline IGF1 (nM/l) & $16 \pm 1.6$ & $12.3 \pm 1.5^{\dagger}$ & $18.9 \pm 1.6$ & $14 \pm 1.6^{\dagger}$ \\
\hline SHBG $(n M / I)$ & $48.3 \pm 7.9$ & $61.9 \pm 9.9^{\dagger}$ & $33.5 \pm 3.4$ & $38.9 \pm 3.5^{\star \S}$ \\
\hline REE (kcal/day) & $1248 \pm 37.3$ & $1305 \pm 38.3$ & $1551 \pm 45.8^{\ddagger}$ & $1608 \pm 64.7$ \\
\hline Basal Fox (mg/min) & $51.7 \pm 6.1$ & $47.1 \pm 5.2$ & $55.5 \pm 5.4$ & $60.6 \pm 4.7$ \\
\hline \multicolumn{5}{|l|}{ Postprandial Fox } \\
\hline At $30 \mathrm{~min}(\mathrm{mg} / \mathrm{min})$ & $45.9 \pm 5.0$ & $27.1 \pm 5.2^{*}$ & $58.5 \pm 6.6$ & $60.9 \pm 6.6^{\S}$ \\
\hline Basal Cox (mg/min) & $55.2 \pm 12.7$ & $76.7 \pm 10.1$ & $92.6 \pm 11.2^{\ddagger}$ & $90.2 \pm 16.5$ \\
\hline \multicolumn{5}{|l|}{ Postprandial Cox } \\
\hline At $30 \mathrm{~min}(\mathrm{mg} / \mathrm{min})$ & $96.4 \pm 13.3 \%$ & $166.9 \pm 15.1^{\dagger}$ & $132.5 \pm 13.6$ & $131.5 \pm 21.5^{\S}$ \\
\hline Total cholesterol (mM/l) & $5.5 \pm 0.3$ & $5.1 \pm 0.3$ & $4.2 \pm 0.2^{\ddagger}$ & $4.0 \pm 0.2$ \\
\hline HDL cholesterol (mM/l) & $1.5 \pm 0.1$ & $1.5 \pm 0.1$ & $1.0 \pm 0.1^{\ddagger}$ & $1.0 \pm 0.1$ \\
\hline Triglycerides (mM/l) & $1.2 \pm 0.2$ & $1.2 \pm 0.2$ & $1.3 \pm 0.2$ & $1.0 \pm 0.1^{*}$ \\
\hline Glucose $(\mathrm{mM} / \mathrm{l})$ & $4.9 \pm 0.1$ & $4.9 \pm 0.1$ & $4.9 \pm 0.2$ & $5.0 \pm 0.1$ \\
\hline LH (IU/I) & - & - & $1.3 \pm 0.1$ & $2.3 \pm 0.2^{\dagger}$ \\
\hline Testosterone (nM/l) & - & - & $14.8 \pm 1.0$ & $22.6 \pm 2.0^{\dagger}$ \\
\hline Calculated free testosterone $(\mathrm{pmol} / \mathrm{l})$ & - & - & $231 \pm 18.8$ & $369 \pm 33.3^{\dagger}$ \\
\hline
\end{tabular}

${ }^{\star} P<0.05$ compared to baseline; ${ }^{\dagger} P<0.01$ compared to baseline; ${ }^{\ddagger} P<0.05$ difference in baseline value in men compared to that in women; ${ }^{\S} P<0.05$ difference in tamoxifen-induced change between men and women. 
A

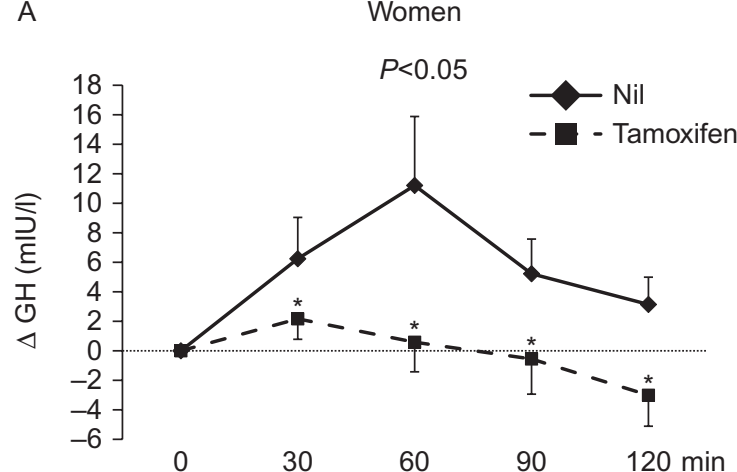

B

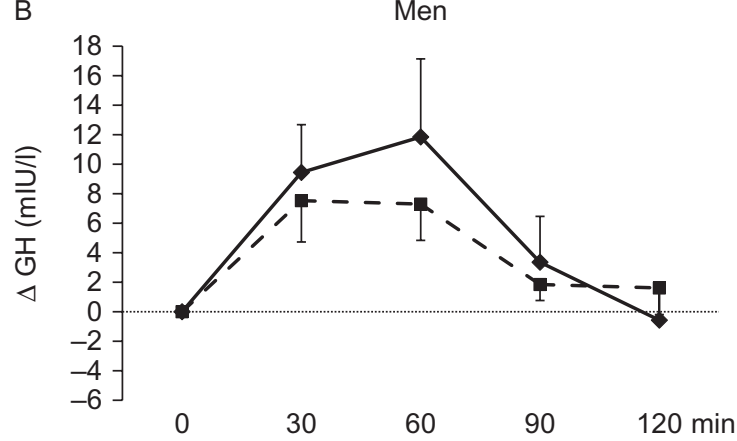

\section{Figure 1}

$\mathrm{GH}$ response to arginine stimulation at baseline (nil) and during tamoxifen treatment in healthy women $(A)$ and men $(B)$. Data are presented as mean increment in serum $\mathrm{GH}$ after arginine infusion over pre-stimulation $\mathrm{GH}$ levels. ${ }^{*} P<0.05$ compared to nil. Conversion factor: $1 \mathrm{mIU} / \mathrm{l}=0.33 \mu \mathrm{g} / \mathrm{l}$.

\section{Results}

\section{Hormones}

Median baseline GH concentrations were 2.1 and $0.7 \mathrm{mIU} / 1$ for women and men respectively. In women, when compared to the baseline study, the GH response to arginine stimulation was significantly attenuated by $20 \mathrm{mg}$ of tamoxifen (median reduction in area under the curve (AUC) by $87 \%$ over $120 \mathrm{~min} ; P<0.05$; Table 1; Fig. 1A). Tamoxifen also significantly reduced the peak GH response to stimulation $(P<0.05$; Table 1$)$. In men, the $\mathrm{GH}$ response to arginine was not significantly reduced by tamoxifen, although a trend was evident (Fig. 1B). Thus, tamoxifen significantly attenuated $\mathrm{GH}$ response to stimulation in women but not in men.

In both women and men, the mean IGF1 level significantly fell during the treatment with $20 \mathrm{mg}$ tamoxifen by $23.5 \pm 5.4$ and $24.8 \pm 6.1 \%$ respectively $(P<0.01$;
Fig. 2A and B). The effect of tamoxifen on circulating IGF1 levels was not significantly different between men and women.

SHBG rose significantly during treatment with tamoxifen in both women and men $(P<0.01$ and $P<0.05$ respectively; Table 1$)$. The increase in SHBG was greater in women than in men $(29.5 \pm 6.4$ vs $20.2 \pm 6.9 \%$ $P=0.05)$.

In men, circulating LH levels rose significantly during tamoxifen treatment by nearly twofold $(P<0.001$; Fig. 3A). Testosterone levels increased during tamoxifen treatment by $52 \pm 14.2 \%(P<0.01$; Fig. 3B $)$. CFT also significantly increased $(\Delta 63.6 \pm 14.8 \% ; P<0.001$; Table 1$)$.

\section{Substrate oxidation and REE}

Tamoxifen did not significantly affect REE, nor the rates of basal Fox or Cox in women and in men (Table 1).

Ingestion of the liquid standardized mixed meal acutely suppressed Fox. In women, Fox fell to a greater degree with tamoxifen treatment during the $2 \mathrm{~h}$ post prandial period compared to the control study $(P<0.05$; Table 1; Fig. 4A). At $30 \mathrm{~min}$, the rate of Fox was $34.6 \pm$ $10.3 \%$ lower during tamoxifen treatment (Table 1) and over the period of $2 \mathrm{~h}$ the area under the curve was lowered by $29.9 \%$. In men, there was no significant difference in postprandial Fox between tamoxifen and control studies. Tamoxifen significantly enhanced the postprandial rise in Cox in women but not men $(P<0.01$; Table 1$)$.

Thus, only in women tamoxifen significantly reduced postprandial fatty acid oxidation rates and increased Cox.

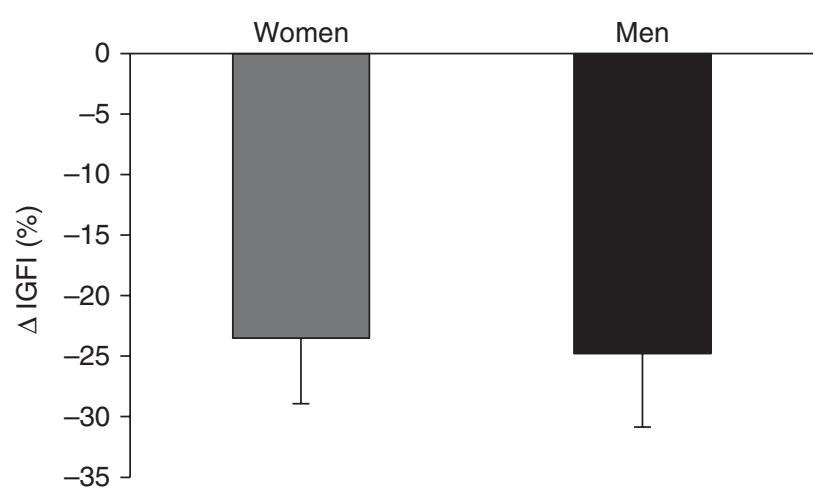

\section{Figure 2}

Percent changes in serum IGF1 levels in women and men during $20 \mathrm{mg}$ tamoxifen treatment. Data are expressed as means \pm s.E.M. 


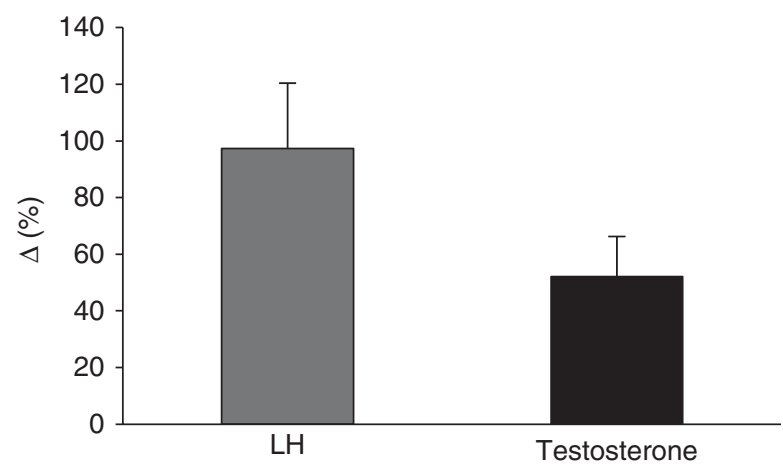

Figure 3

Percent changes in serum $\mathrm{LH}$ and testosterone levels in men during $20 \mathrm{mg}$ tamoxifen treatment. Data are expressed as means \pm s.E.M.

\section{Other endpoints}

In women, tamoxifen did not significantly change serum levels of total cholesterol, HDL cholesterol, TGs and glucose (Table 1). In men, tamoxifen did not significantly change total cholesterol, HDL cholesterol and glucose, whereas there was a small but significant $(P<0.05)$ reduction in TG levels (Table 1 ).

\section{Discussion}

Tamoxifen significantly attenuated GH response to stimulation in women but not in men. In both women and men, tamoxifen significantly increased SHBG levels, a response that was greater in women. Tamoxifen significantly reduced IGF1 levels in men and women by a similar degree. In men, it increased circulating levels of LH and testosterone. Tamoxifen significantly reduced postprandial Fox and increased Cox in women but not in men. Thus, tamoxifen exerted gender-related effects on GH secretion, substrate oxidation and SHBG but not on IGF1.

Central stimulation of GH secretion in both men and women by testosterone require aromatization to estrogen $(1,2)$. Studies in rodents also provide evidence that local estrogen production drives GH secretion via aromatisation, from the observation that pituitaries in aromatase knockout (ArKO) mice are hypoplastic and GH levels low (22). In men with aromatase deficiency, the GH response to stimulation is markedly blunted and is not restored by systemic $\mathrm{E}_{2}$ replacement (23). These observations indicate that local estrogen production is required for the central stimulation of GH secretion. The present study shows that tamoxifen predictably reduced GH secretion through a central estrogen antagonistic effect.

$\mathrm{E}_{2}$ derived from aromatisation also mediates the negative feedback of testosterone on LH secretion $(3,24)$. Thus, by blocking central estrogen action, tamoxifen removes testosterone feedback inhibition, enhancing LH secretion and increasing testosterone production in men (5). Tamoxifen suppressed the GH axis to a lesser degree in men than in women. This may be explained by higher testosterone levels in men increasing substrate availability for aromatization to $E_{2}$, mitigating suppression of $\mathrm{GH}$ secretion in men.

An interesting observation in the present study is that the greater inhibition of GH secretion by tamoxifen was not accompanied by a greater reduction in IGF1 levels in women compared to men. In addition to its central effect, tamoxifen also acts directly on the liver inhibiting IGF1 production via an estrogen agonist effect (25). The observation that IGF1 did not fall to a greater degree in women suggests that tamoxifen may be exerting a greater hepatic effect in men than in women. This could arise from a gender difference in hepatocyte response to tamoxifen or in drug metabolism of tamoxifen.
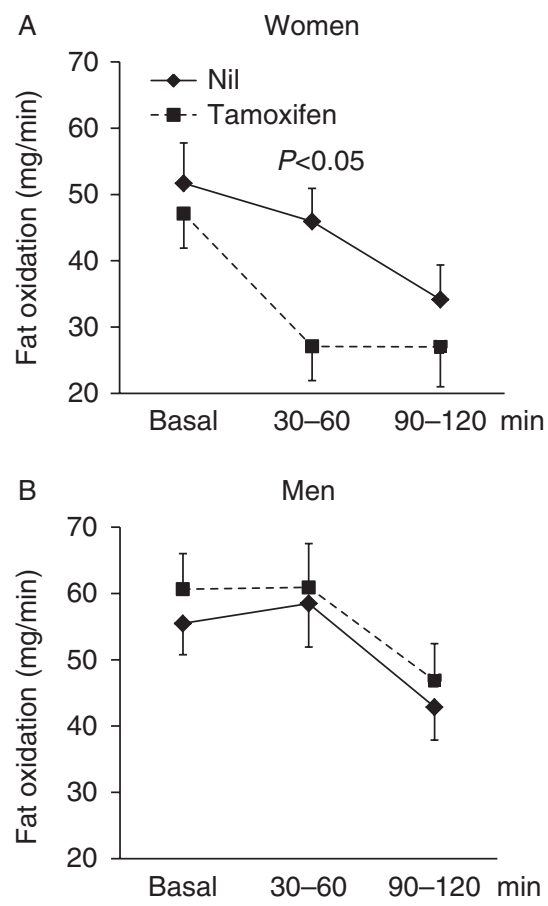

\section{Figure 4}

Fat oxidation rates in a fasting state (Basal) and postprandially at 30-60 min and 90-120 min after the mixed meal in women (A) and men (B). Data are expressed as means \pm s.E.M. 
SHBG, an estrogen-responsive hepatic protein, may be used to compare the hepatic responsiveness of tamoxifen between the sexes. The observation that SHBG increased less in men suggests a lesser, rather than a greater estrogenic effect in men. However SHBG is also an androgen-responsive hepatic protein, which is reduced by testosterone, evident from men having a lower baseline mean SHBG concentration. The compensatory rise of testosterone could blunt the direct SHBG enhancing estrogen-like effect of the drug. Therefore SHBG changes cannot be used as a reliable hepatic marker of tamoxifen action in this study.

Can a secondary increase in testosterone induced by tamoxifen influence the IGF1 response in men? We have previously reported that testosterone does not increase circulating IGF1 in hypopituitary men with GH deficiency (GHD) (13). When replaced with GH, addition of testosterone in hypopituitary men has minimal effect on circulating IGF1 (26). Thus, the evidence indicates that testosterone increases circulating IGF1 by stimulating GH secretion with little contribution from direct hepatic action. Therefore, the increase in testosterone levels by tamoxifen is unlikely to influence its inhibitory effect on hepatic IGF1 production. Another possible explanation may be a gender difference in tamoxifen metabolism.
In rodents, hepatic expression of cytochrome P4503A, an enzyme that metabolizes tamoxifen, is lower in males than in females (27). If this is true in humans, higher blood concentrations of tamoxifen could explain its more potent hepatic estrogen-like effect in men. The collective evidence indicates that tamoxifen exerts a greater inhibitory hepatic IGF1 effect in men than in women, but the mechanisms involved are unclear.

Tamoxifen suppressed Fox in women but not men, which can be explained in part by the greater suppression in women of $\mathrm{GH}$ secretion which stimulates Fox. We cannot exclude additional mechanisms including a direct inhibitory effect of tamoxifen on hepatic fatty acid metabolism. Several in-vitro studies have reported that tamoxifen induces hepatocyte steatosis, up-regulates SREBP-1c and its downstream target genes, increases fatty acid synthesis, impairs mitochondrial $\beta$-oxidation and respiration, and reduces hepatic TG secretion $(28,29)$. Some studies report no direct effect of tamoxifen on hepatocyte fatty acid oxidation, whereas systemic treatment of tamoxifen in mice substantially increases hepatic TG content and activates fatty acid synthesis (30). However, no gender difference in the direct effect of tamoxifen has been reported. Therefore, in our study, the reduction in fatty acid oxidation in women may not reflect
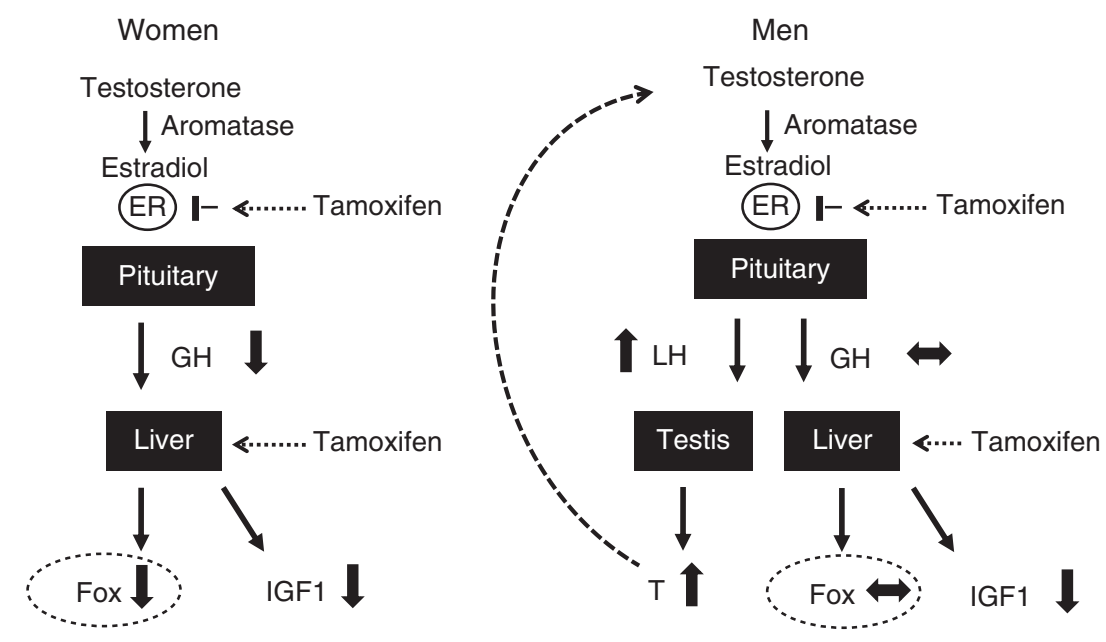

\section{Figure 5}

In women, tamoxifen attenuates estrogen-stimulated $\mathrm{GH}$ secretion, by blocking central estrogen receptors. In the liver, it exerts estrogen-like effects that inhibit GH receptor signalling, by reducing IGF1 production and fat oxidation. In men, tamoxifen treatment stimulates $\mathrm{LH}$, which is followed by an increase in testosterone levels. The increase in testosterone counteracts the inhibitory effect of tamoxifen on GH secretion, resulting in a no net effect on $\mathrm{GH}$ secretion, contrary to that in women. As both testosterone and GH increase fat oxidation, the stimulation of gonadal axis and small inhibitory effect on GH-IGF1 axis results in a no net effect on fat oxidation in men. 
gender specific direct hepatic effect of tamoxifen on fat metabolism but rather an effect secondary to reduced GH secretion.

Is the transient post-prandial suppression of Fox clinically significant? The reduction in postprandial Fox from our study was on average $13 \mathrm{mg} / \mathrm{min}$ over $2 \mathrm{~h}$. If extrapolated to three meals per day, this may equate to an accumulation of fat of about $5 \mathrm{~g} /$ day approximating $1.8 \mathrm{~kg}$ per year. Some studies in women with breast cancer have observed that tamoxifen causes weight gain. In a cohort of more than 500 newly diagnosed women with breast cancer, tamoxifen increased weight by $1.0 \mathrm{~kg}$ over 1 year (31). However, another long-term study in breast cancer patients showed no difference in weight gain between tamoxifen users and non-users (32). However weight is not a reliable indicator of adiposity. We had previously reported the metabolic impact of oral estrogen treatment to postmenopausal women who gained $1.2 \mathrm{~kg}$ body fat over 6 months, which occurred without a change in body weight because of a concurrent loss of lean body mass (LBM) (20). These body compositional changes occurred in parallel with the post-prandial suppression of Fox of $8 \mathrm{mg} / \mathrm{min}$ and sustained fall in IGF1. Thus, the biochemical changes induced by oral estrogens are similar to those observed with tamoxifen in the present study. Based on these findings, we predict that long-term treatment with tamoxifen is likely to induce similar detrimental changes in body composition.

Tamoxifen is used for treatment of breast cancer in both sexes, for infertility and male gynecomastia. Based on our findings we can predict a gender difference in tamoxifen-related side-effects. In women, the dual reduction of $\mathrm{GH}$ and IGF1 production by tamoxifen induces a state of GHD. GHD is characterized by a reduction in Fox, an increase in fat mass and the development of hepatic steatosis $(33,34)$. Hepatic steatosis is a frequent complication of tamoxifen in women treated for breast cancer (35). As GH stimulates hepatic Fox and TG export (36), the evidence supports a metabolic significant and detrimental impact of tamoxifen on liver function via suppression of the GH-IGF axis $(37,38)$. In men, the activation of the gonadal axis ameliorates the suppression of the GH/IGF1 axis evident in women. Therefore, men are less at risk of the detrimental metabolic consequences of tamoxifen.

A weakness of this study is that it was not placebocontrolled. However, the outcome measures are objective. We did not measure IGF1 binding proteins, but it is known that SERMs increase circulating IGFBP-3 levels $(37,39)$, which in the face of reduced IGF1 may result in significant reduction in IGF1 bioavailability and a loss of anabolism. We did not assess other aspects of lipid metabolism, such as lipolysis, TG synthesis or hepatic export. Because GH positively regulates VLDL synthesis (36), we predict that tamoxifen may inhibit hepatic TG export as a consequence of its suppression of the $\mathrm{GH}$ axis. This effect may explain the development of steatosis with tamoxifen therapy (35).

In summary, this study demonstrates that tamoxifen suppresses the GH-IGF system with the effects greater in women than in men. We propose that the attenuated effect in men can be explained by co-activation of the pituitary gonadal system as illustrated in Fig. 5. In women, tamoxifen reduces $\mathrm{GH}$ secretion and $\mathrm{GH}$ action inhibiting hepatic IGF1 production and Fox in the liver. In men, concurrent central stimulation of the gonadal axis increases circulating testosterone concentration which neutralises the central inhibition of GH secretion by tamoxifen. The additional stimulatory effect of testosterone on Fox abrogates the suppression of hepatic Fox observed in women (Fig. 5).

We conclude that tamoxifen suppresses the secretion and metabolic action of $\mathrm{GH}$, effects that are greater in women than in men. Men are less at risk of the metabolic consequences of SERMs, such as development of obesity and hepatic steatosis.

\section{Declaration of interest}

The authors declare that there is no conflict of interest that could be perceived as prejudicing the impartiality of the research reported.

\section{Funding}

This work was supported by the National Health and Medical Research Council of Australia.

\section{Acknowledgements}

We thank Alphapharm for providing Genox. We gratefully thank research nurses Selina Sutton and Surya Sutanto for their clinical assistance and the Endocrinology Laboratory, Royal Prince Alfred Hospital, Sydney, Australia.

\section{References}

1 Weissberger AJ \& Ho KK. Activation of the somatotropic axis by testosterone in adult males: evidence for the role of aromatization. Journal of Clinical Endocrinology and Metabolism 199376 1407-1412.

2 Birzniece V, Sata A, Sutanto S \& Ho KK. Paracrine regulation of growth hormone secretion by estrogen in women. Journal of Clinical Endocrinology and Metabolism 201095 3771-3776. (doi:10.1210/jc. 2010-0476) 
3 Rochira V, Zirilli L, Genazzani AD, Balestrieri A, Aranda C, Fabre B, Antunez P, Diazzi C, Carani C \& Maffei L. Hypothalamic-pituitarygonadal axis in two men with aromatase deficiency: evidence that circulating estrogens are required at the hypothalamic level for the integrity of gonadotropin negative feedback. European Journal of Endocrinology 2006155 513-522. (doi:10.1530/eje.1.02254)

4 Birzniece V, Sutanto S \& Ho KK. Gender difference in the neuroendocrine regulation of growth hormone axis by selective estrogen receptor modulators. Journal of Clinical Endocrinology and Metabolism 201297 E521-E527. (doi:10.1210/jc.2011-3347)

5 Birzniece V, Sata A, Sutanto S \& Ho KK. Neuroendocrine regulation of growth hormone and androgen axes by selective estrogen receptor modulators in healthy men. Journal of Clinical Endocrinology and Metabolism 201095 5443-5448. (doi:10.1210/jc.2010-1477)

6 Snyder PJ, Peachey H, Berlin JA, Hannoush P, Haddad G, Dlewati A, Santanna J, Loh L, Lenrow DA, Holmes JH, Kapoor SC, Atkinson LE \& Strom BL. Effects of testosterone replacement in hypogonadal men. Journal of Clinical Endocrinology and Metabolism 200085 2670-2677.

7 Wang C, Swerdloff RS, Iranmanesh A, Dobs A, Snyder PJ, Cunningham G, Matsumoto AM, Weber T \& Berman N. Transdermal testosterone gel improves sexual function, mood, muscle strength, and body composition parameters in hypogonadal men. Journal of Clinical Endocrinology and Metabolism 200085 2839-2853.

8 Wang C, Cunningham G, Dobs A, Iranmanesh A, Matsumoto AM, Snyder PJ, Weber T, Berman N, Hull L \& Swerdloff RS. Long-term testosterone gel (AndroGel) treatment maintains beneficial effects on sexual function and mood, lean and fat mass, and bone mineral density in hypogonadal men. Journal of Clinical Endocrinology and Metabolism 200489 2085-2098. (doi:10.1210/jc.2003-032006)

9 Woodhouse LJ, Mukherjee A, Shalet SM \& Ezzat S. The influence of growth hormone status on physical impairments, functional limitations, and health-related quality of life in adults. Endocrine Reviews 200627 287-317. (doi:10.1210/er.2004-0022)

10 Gibney J, Wallace JD, Spinks T, Schnorr L, Ranicar A, Cuneo RC, Lockhart S, Burnand KG, Salomon F, Sonksen PH \& Russell-Jones D. The effects of 10 years of recombinant human growth hormone (GH) in adult GH-deficient patients. Journal of Clinical Endocrinology and Metabolism 199984 2596-2602. (doi:10.1210/jcem.84.8.5916)

11 Rodriguez-Arnao J, Jabbar A, Fulcher K, Besser GM \& Ross RJ. Effects of growth hormone replacement on physical performance and body composition in GH deficient adults. Clinical Endocrinology $1999 \mathbf{5 1}$ 53-60. (doi:10.1046/j.1365-2265.1999.00737.x)

12 Gibney J, Healy ML \& Sonksen PH. The growth hormone/insulin-like growth factor-I axis in exercise and sport. Endocrine Reviews 200728 603-624. (doi:10.1210/er.2006-0052)

13 Gibney J, Wolthers T, Johannsson G, Umpleby AM \& Ho KK. Growth hormone and testosterone interact positively to enhance protein and energy metabolism in hypopituitary men. American Journal of Physiology. Endocrinology and Metabolism 2005289 E266-E271. (doi:10.1152/ajpendo.00483.2004)

14 Arslanian S \& Suprasongsin C. Testosterone treatment in adolescents with delayed puberty: changes in body composition, protein, fat, and glucose metabolism. Journal of Clinical Endocrinology and Metabolism 199782 3213-3220.

15 Mauras N, Hayes V, Welch S, Rini A, Helgeson K, Dokler M, Veldhuis JD \& Urban RJ. Testosterone deficiency in young men: marked alterations in whole body protein kinetics, strength, and adiposity. Journal of Clinical Endocrinology and Metabolism 199883 1886-1892.

16 Birzniece V, Meinhardt UJ, Handelsman DJ \& Ho KK. Testosterone stimulates extra-hepatic but not hepatic fat oxidation (Fox): comparison of oral and transdermal testosterone administration in hypopituitary men. Clinical Endocrinology 200971 715-721. (doi:10.1111/j.1365-2265.2009.03524.x)

17 Zhao JT, Cowley MJ, Lee P, Birzniece V, Kaplan W \& Ho KK. Identification of novel GH-regulated pathway of lipid metabolism in adipose tissue: a gene expression study in hypopituitary men.
Journal of Clinical Endocrinology and Metabolism 201196 E1188-E1196. (doi:10.1210/jc.2010-2679)

18 Fideleff HL, Frigeri AE, Sobrado PG, Llano MN, Ruibal GF \& Boquete HR. Reproducibility and variability of the arginine test in normal adults. Comparision between sexes. Medicina 199959 249-253.

19 Ferrannini E. The theoretical bases of indirect calorimetry: a review. Metabolism 198837 287-301. (doi:10.1016/0026-0495(88)90110-2)

20 O'Sullivan AJ, Crampton LJ, Freund J \& Ho KK. The route of estrogen replacement therapy confers divergent effects on substrate oxidation and body composition in postmenopausal women. Journal of Clinical Investigation 1998102 1035-1040. (doi:10.1172/JCI2773)

21 Ly LP \& Handelsman DJ. Empirical estimation of free testosterone from testosterone and sex hormone-binding globulin immunoassays. European Journal of Endocrinology 2005152 471-478. (doi:10.1530/eje.1. 01844)

22 Yan M, Jones ME, Hernandez M, Liu D, Simpson ER \& Chen C. Functional modification of pituitary somatotropes in the aromatase knockout mouse and the effect of estrogen replacement. Endocrinology 2004145 604-612. (doi:10.1210/en.2003-0646)

23 Rochira V, Zirilli L, Maffei L, Premrou V, Aranda C, Baldi M, Ghigo E, Aimaretti G, Carani C \& Lanfranco F. Tall stature without growth hormone: four male patients with aromatase deficiency. Journal of Clinical Endocrinology and Metabolism 201095 1626-1633. (doi:10.1210/ jc.2009-1743)

24 Gooren LJ, van der Veen EA, van Kessel H \& Harmsen-Louman W. Estrogens in the feedback regulation of gonadotropin secretion in men: effects of administration of estrogen to agonadal subjects and the antiestrogen tamoxifen and the aromatase inhibitor delta'-testolactone to eugonadal subjects. Andrologia 198416 568-577. (doi:10.1111/j. 1439-0272.1984.tb00414.x)

25 Leung KC, Doyle N, Ballesteros M, Sjogren K, Watts CK, Low TH, Leong GM, Ross RJ \& Ho KK. Estrogen inhibits GH signaling by suppressing GH-induced JAK2 phosphorylation, an effect mediated by SOCS-2. PNAS 2003100 1016-1021. (doi:10.1073/pnas.0337600100)

26 Birzniece V, Meinhardt UJ, Umpleby MA, Handelsman DJ \& Ho KK. Interaction between testosterone and growth hormone on whole-body protein anabolism occurs in the liver. Journal of Clinical Endocrinology and Metabolism 201196 1060-1067. (doi:10.1210/jc.2010-2521)

27 Cheung C, Yu AM, Chen CS, Krausz KW, Byrd LG, Feigenbaum L, Edwards RJ, Waxman DJ \& Gonzalez FJ. Growth hormone determines sexual dimorphism of hepatic cytochrome P450 3A4 expression in transgenic mice. Journal of Pharmacology and Experimental Therapeutics 2006316 1328-1334. (doi:10.1124/jpet.105.094367)

28 Zhao F, Xie P, Jiang J, Zhang L, An W \& Zhan Y. The effect and mechanism of tamoxifen-induced hepatocyte steatosis in vitro. International Journal of Molecular Sciences 201415 4019-4030. (doi:10.3390/ijms15034019)

29 Larosche I, Letteron P, Fromenty B, Vadrot N, Abbey-Toby A, Feldmann G, Pessayre D \& Mansouri A. Tamoxifen inhibits topoisomerases, depletes mitochondrial DNA, and triggers steatosis in mouse liver. Journal of Pharmacology and Experimental Therapeutics 2007321 526-535. (doi:10.1124/jpet.106.114546)

30 Cole LK, Jacobs RL \& Vance DE. Tamoxifen induces triacylglycerol accumulation in the mouse liver by activation of fatty acid synthesis. Hepatology 201052 1258-1265. (doi:10.1002/hep.23813)

31 Goodwin PJ, Ennis M, Pritchard KI, McCready D, Koo J, Sidlofsky S, Trudeau M, Hood N \& Redwood S. Adjuvant treatment and onset of menopause predict weight gain after breast cancer diagnosis. Journal of Clinical Oncology 199917 120-129.

32 Lankester KJ, Phillips JE \& Lawton PA. Weight gain during adjuvant and neoadjuvant chemotherapy for breast cancer: an audit of 100 women receiving FEC or CMF chemotherapy. Clinical Oncology 2002 14 64-67. (doi:10.1053/clon.2001.0014)

33 Takahashi Y, Iida K, Takahashi K, Yoshioka S, Fukuoka H, Takeno R, Imanaka M, Nishizawa H, Takahashi M, Seo Y, Hayashi Y, Kondo T, Okimura Y, Kaji H, Kitazawa R, Kitazawa S \& Chihara K. Growth 
hormone reverses nonalcoholic steatohepatitis in a patient with adult growth hormone deficiency. Gastroenterology 2007132 938-943. (doi:10.1053/j.gastro.2006.12.024)

34 Ichikawa T, Nakao K, Hamasaki K, Furukawa R, Tsuruta S, Ueda Y, Taura N, Shibata H, Fujimoto M, Toriyama K \& Eguchi K. Role of growth hormone, insulin-like growth factor 1 and insulin-like growth factorbinding protein 3 in development of non-alcoholic fatty liver disease. Hepatology International 20071 287-294. (doi:10.1007/s12072-007-9007-4)

35 Nishino M, Hayakawa K, Nakamura Y, Morimoto T \& Mukaihara S. Effects of tamoxifen on hepatic fat content and the development of hepatic steatosis in patients with breast cancer: high frequency of involvement and rapid reversal after completion of tamoxifen therapy. AJR. American Journal of Roentgenology 2003180 129-134. (doi:10.2214/ ajr.180.1.1800129)

36 Christ ER, Cummings MH, Albany E, Umpleby AM, Lumb PJ, Wierzbicki AS, Naoumova RP, Boroujerdi MA, Sonksen PH \& Russell-Jones DL. Effects of growth hormone (GH) replacement therapy on very low density lipoprotein apolipoprotein B100 kinetics in patients with adult GH deficiency: a stable isotope study. Journal of Clinical Endocrinology and Metabolism 199984 307-316.

37 Gibney J, Johannsson G, Leung KC \& Ho KK. Comparison of the metabolic effects of raloxifene and oral estrogen in postmenopausal and growth hormone-deficient women. Journal of Clinical Endocrinology and Metabolism 200590 3897-3903. (doi:10.1210/jc.2005-0173)

38 Birzniece V, Meinhardt U, Gibney J, Johannsson G, Baxter RC, Seibel MJ $\&$ Ho KK. Modulatory effect of raloxifene and estrogen on the metabolic action of growth hormone in hypopituitary women. Journal of Clinical Endocrinology and Metabolism 201095 2099-2106. (doi:10.1210/jc.2009-2743)

39 Birzniece V, Meinhardt UJ, Gibney J, Johannsson G, Armstrong N, Baxter RC \& Ho KK. Differential effects of raloxifene and estrogen on body composition in growth hormone-replaced hypopituitary women. Journal of Clinical Endocrinology and Metabolism 201297 1005-1012. (doi:10.1210/jc.2011-2837)

Received 23 April 2015

Revised version received 7 July 2015

Accepted 21 July 2015 